\title{
Conformational Control of Energy Transfer: A Mechanism for Biocompatible Nanocrystal-Based Sensors
}

\section{Citation}

Kay, Euan R., Jungmin Lee, Daniel G. Nocera, and Moungi G. Bawendi. 2012. “Conformational Control of Energy Transfer: A Mechanism for Biocompatible Nanocrystal-Based Sensors." Angewandte Chemie International Edition 52 (4) (December 6): 1165-1169. doi:10.1002/ anie.201207181.

\section{Published Version}

doi:10.1002/anie.201207181

\section{Permanent link}

http://nrs.harvard.edu/urn-3:HUL.InstRepos:33464245

\section{Terms of Use}

This article was downloaded from Harvard University's DASH repository, and is made available under the terms and conditions applicable to Open Access Policy Articles, as set forth at http:// nrs.harvard.edu/urn-3:HUL.InstRepos:dash.current.terms-of-use\#OAP

\section{Share Your Story}

The Harvard community has made this article openly available.

Please share how this access benefits you. Submit a story. 


\title{
Conformational control of energy transfer: a new mechanism for biocompatible nanocrystal-based sensors"
}

\author{
Euan R. Kay ${ }^{\dagger} \S$, Jungmin Lee ${ }^{\dagger}$, Daniel G. Nocera, and Moungi G. Bawendi ${ }^{*}$ \\ Department of Chemistry, Massachusetts Institute of Technology, 77 Massachusetts Ave., \\ Cambridge MA 02139-4307 (USA)
}

\begin{abstract}
Fold-up fluorophore: A new paradigm for designing self-referencing fluorescent nanosensors is demonstrated by interfacing a $\mathrm{pH}$-triggered molecular conformational switch with quantum dots. Analytedependent, large-amplitude conformational motion controls the distance between the nanocrystal energy donor and an organic FRET acceptor. The result is a fluorescence signal capable of reporting $\mathrm{pH}$ values from individual endosomes in living cells.
\end{abstract}

\section{Keywords}

biosensors; fluorescent probes; quantum dots; molecular devices; molecular machines

\begin{abstract}
Recent advances have given access to myriad engineered nanomaterials, ranging from functional nanotubes and fluorescent nanocrystals (NCs) to oligonucleotide self-assemblies and polymer nanoparticles. The integration of these nanomaterials with dynamic molecular components will likely be a key concept in realizing their full potential. ${ }^{[1]}$ In this regard, combining NCs with molecular machines presents an unexplored strategy for modulating $\mathrm{NC}$ properties in response to a specific stimulus. Here we outline this new paradigm through designing a self-referencing, NC-nanomachine-based sensor. A conformational switch, activated by a chosen specific analyte (here, $\mathrm{H}^{+}$ions), is used to vary the efficiency of energy transfer between the $\mathrm{NC}$ and an appended species. The analyte concentration is reported by a ratiometric fluorescence signal that is quantifiable and robust across a variety of imaging conditions, allowing for the high-resolution measurement of $\mathrm{pH}$ within individual endosomes in HeLa cells. This study thus exemplifies the strategy of disconnecting sensing and reporting functions to create a universal fluorescent sensor design that addresses many of the challenges associated with harnessing the unique optical properties of NCs.
\end{abstract}

Several intrinsic properties serve to make NC fluorophores attractive tools for advanced imaging applications, ${ }^{[2]}$ such as intravital multi-photon laser scanning microscopy, multiplexing and single receptor tracking. ${ }^{[3]}$ In particular, their narrow and tunable emission spectra, high quantum yields, broad absorption profiles, high photostability, and large single and multi-photon cross sections have propelled NCs to become useful complements to

\footnotetext{
**ERK was supported by The Royal Commission for the Exhibition of 1851. The work received support from the NIH through grants 5-U54-CA119349-05 (M.G.B.) and 5R01CA126642-02 (M.G.B., D.G.N). The Biophysical Instrumentation Facility for the Study of Complex Macromolecular Systems and DCIF at MIT (NSF-0070319, NIH GM68762 and CHE-980806, DBI-979582) are gratefully acknowledged. Supporting information for this article is available on the WWW under http://www.angewandte.org or from the author. *Fax: (+1) 617452 2708, mgb@mit.edu, Homepage: http://nanocluster.mit.edu. \Current address: EaStChem School of Chemistry, University of St Andrews, North Haugh, St Andrews, KY16 9ST (UK)

$\dagger$ These authors contributed equally to this work
} 
organic fluorophores and fluorescent proteins. These attributes provide strong motivation for finding ways to incorporate NCs into fluorescent sensors: fluorescent sensors possessing the optical properties of NCs will enable the noninvasive quantification of biochemical species with high spatial and temporal resolution and with the ability to track changes over extended periods from within complex living environments. ${ }^{[4]}$

One of the most promising concepts for constructing NC sensors is to attach a second chromophore (such as an organic dye or a transition metal complex) that can act as a fluorescence resonant energy transfer (FRET) partner with the NC. ${ }^{[5]} \mathrm{NC}$ fluorophores make ideal FRET donors - their narrow emission features can easily be tuned to match the absorption spectrum of any acceptor, thus endowing the sensing construct with the favorable optical properties of the NC. However, existing NC-based fluorescent sensors have yet to demonstrate compelling performance. While analyte-induced cleavage, ${ }^{[6]}$ displacement ${ }^{[7]}$ or chemical modification ${ }^{[8]}$ can irreversibly modulate a FRET interaction and confer detection abilities on a $\mathrm{NC}$ construct, continuous monitoring of analyte levels requires a reversible response to analyte concentration. Furthermore fluorescent sensing within living environments must ultimately address confounding factors such as variations in probe concentration, excitation intensity, and collection efficiency, ${ }^{[8 \mathrm{a}, 9]}$ necessitating a selfreferencing output, commonly achieved by taking a ratio of fluorescence intensities at two different wavelengths. The majority of reported NC-based sensors have thus exploited analyte-sensitive dyes to provide both sensing and signaling functions, but resulting in several significant shortcomings including the limited variety of available analyteresponsive dyes and difficulty of use in biological environments. ${ }^{[10]}$

Here we introduce a different approach that circumvents these limitations by separating the optical signaling from the chemical sensing components. A chemically insensitive $\mathrm{NC}-$ molecule FRET pair is connected through a linker that undergoes a reversible conformational change upon binding to the analyte (Figure 1a). As energy-transfer interactions are extremely sensitive to distance, conformational changes in the linker lead to a substantial change in optical signal. Monitoring the emission from both fluorophores therefore provides a sensitive, ratiometric response that can be used to track analyte concentrations within microscopic biological environments. Maintaining specific $\mathrm{pH}$ values and gradients is essential for many biological processes such as protein folding. Furthermore, in the extracellular space, low $\mathrm{pH}$ is an important hallmark of many tumor microenvironments. These bio-applications and others provide an imperative for improved tools capable of accurately monitoring $\mathrm{pH}$ in living systems with high spatial and temporal resolution. ${ }^{[11]}$

Certain cytosine-rich oligonucleotide sequences are known to undergo folding or unfolding in response to changes in $\mathrm{pH}$, depending on the protonation state of the cytosine imino group. ${ }^{[12]}$ Recently, a ratiometric $\mathrm{pH}$ sensor was created by appending two molecular fluorophores to one such sequence, allowing $\mathrm{pH}$ changes in the endosomes of haemocytes to be monitored. ${ }^{[13]}$ To create a NC-based sensor in which a reversible conformational change is transduced into an optical response, a simpler $\mathrm{pH}$-responsive oligonucleotide was selected (Figure 1c). This sequence is capable of cycling between two well-defined conformations: an extended duplex-overhang structure and a folded CT-motif triplex. The effective $\mathrm{p} K_{\mathrm{a}}$ for this transition is ideal for achieving greatest sensitivity in mildly acidic biological environments. ${ }^{[14]}$ The relatively rigid DNA adduct helps to ensure that the two ends of the switch are held far apart in the unfolded state. Protonation of cytosine imino groups in the single-stranded region results in folding to allow Hoogsteen triplet base-pairing interactions in the major groove of the duplex. This conformational change dramatically alters the distance between the termini of the DNA adduct (Figure 1c). In order to build the NC-based $\mathrm{pH}$ sensor, 5(6)-carboxy-X-rhodamine (Rox) - a pH insensitive fluorophore - was installed 
at the 3 ' overhang end of the 35-mer (Figure 1c). At the opposite end of the construct, a thiol at the $3^{\prime}$ terminus of the 16-mer acted as a handle for attachment to polymer-coated NCs.

We have previously demonstrated compact, biocompatible and bright NCs based on polymeric imidazole ligands (PILs) such as 1 (Figure 1b). ${ }^{[15]}$ Water-soluble CdSe/CdS core-shell NCs, emitting at $560 \mathrm{~nm}$, were prepared using PIL 1. Activation of the primary amines with the heterobifunctional linker sulfosuccinimidyl-4-(Nmaleimidomethyl) cyclohexane-1-carboxylate (sulfo-SMCC) then allowed covalent attachment of the thiol on the hybridized double-stranded oligonucleotide (see supplementary information for details). Successful conjugation of the oligonucleotide to the nanoparticles was confirmed by the UV-Vis absorption spectrum, featuring both the inorganic NC and organic dye peaks (Figure S2). A linear fit of this spectrum to reference NC and DNA-Rox spectra gave an average coupling stoichiometry of 3.6 DNA-Rox units per NC.

When placed in phosphate buffers of varying $\mathrm{pH}$ and excited at $460 \mathrm{~nm}$, the construct exhibits a time-invariant emission, comprising two features at wavelengths corresponding to the NC $\left(\lambda_{\text {PLmax }}=560 \mathrm{~nm}\right)$ and Rox $\left(\lambda_{\text {PLmax }}=610 \mathrm{~nm}\right)$ components (Figure 2a). As Rox absorbs minimally at $460 \mathrm{~nm}$, this indicates excitation through energy transfer from the NC. On varying $\mathrm{pH}$ from 8.0 to 6.1 , a dramatic change in the relative intensity of these two features is observed (Figure 2). At high pH values, strong emission from the NC and poor FRET efficiency to Rox is observed, consistent with the unfolded oligonucleotide switch holding the donor and acceptor far apart. As $\mathrm{pH}$ is lowered, $\mathrm{NC}$ emission becomes increasingly quenched, with concomitant enhancement of emission from the Rox. This is consistent with increasing FRET efficiency from the NC to Rox as the folded triplex conformation of the oligonucleotide brings the NC energy donor and Rox energy acceptor closer in space.

A practical parameter for expressing sensor response is the proportion of green channel emission (using $590 \mathrm{~nm}$ as a cutoff) compared to the total integrated emission. A plot of this ratio shows a sigmoidal response (Figure $2 b$, black squares), with maximum sensitivity around $\mathrm{pH} 7.0$, in line with the characteristics of the oligonucleotide conformational switch. ${ }^{[14]}$ This $\mathrm{pH}$ range for conformational switching is ideal for imaging mildly acidified biological microenvironments. The sensor response was found to be robust to changes in both temperature and in electrolyte content (Figure 2c), it was reproducible across several samples and the construct could be recovered, stored and re-used with no adverse effects (see supplementary information). Furthermore, a control construct with Rox dyes coupled directly to amino-PIL coated NCs with no oligonucleotide linker showed no variation in the ratio of emission across the same $\mathrm{pH}$ range (Figure 2b, blue circles).

A deeper understanding of the underlying chemomechanical and photophysical processes can be gained by examining the Förster model, which describes well the efficiency of energy transfer from a NC to an acceptor conjugated to it. When multiple acceptors are conjugated to each NC, the ensemble FRET response can be reproduced by assuming a Poisson distribution of coupling stoichiometries. ${ }^{[16]}$ The equations for these calculations are presented in the supplementary information. Comparing a set of modeled FRET efficiencies to the experimentally observed efficiencies (Figure $2 \mathrm{~d}$ ) at low and high $\mathrm{pH}$, we can infer that the donor-acceptor separations in the all-folded and all-unfolded states are $6.3 \mathrm{~nm}$ and 9.4 $\mathrm{nm}$, respectively (Figure S11). These values are consistent with the physical dimensions of the sensor construct measured by dynamic light scattering (DLS) measurements (Figure 2e). The sensor hydrodynamic radius was found to be invariant with $\mathrm{pH}$ at $9.4 \mathrm{~nm}$. This corresponds very well with the donor-acceptor distance calculated for the unfolded state using FRET theory and suggests that the size of the nanoconstruct is defined by the doublestranded DNA region (including its solvation shell) irrespective of $\mathrm{pH}$. In the unfolded state, 
the single-stranded component does not extend into solution beyond the existing solvation shell. Furthermore, the hydrodynamic radius of the PIL-coated NCs prior to conjugation with the DNA was measured as $6.1 \mathrm{~nm}$, suggesting that in the folded state the Rox dye is located as close to the $\mathrm{NC}$ as possible (6.3 $\mathrm{nm}$ from FRET), without penetrating the polymer coating.

Robust maintenance of the sensor response under a variety of environmental conditions in vitro gives confidence that the design can be applied to image $\mathrm{pH}$ variation in living systems. As a proof of concept, we probed the $\mathrm{pH}$ of endosomes in human adenocarcinoma cells. It is well known that during endosome maturation, there is a significant $\mathrm{pH}$ drop from early endosomes to the late endosomes through action of $\mathrm{H}^{+}$-ATPases, ${ }^{[17]}$ yet it remains challenging to probe live cell endosome $\mathrm{pH}$ values, track the acidification of endosomes over time, and develop a complete understanding of this dynamic process.

The sensor response was first calibrated by imaging in buffers of varying $\mathrm{pH}$ under a confocal microscope. The sample was excited at $488 \mathrm{~nm}$ and the image acquired simultaneously in the green NC channel (560-580 nm) and the red Rox channel (590-620 $\mathrm{nm})$. The proportion of green channel intensity as a fraction of the total intensity at different $\mathrm{pH}$ values is shown in Figure 3a. Although absolute intensities are affected by changing excitation wavelength and green and red channel widths, the power of the ratiometric approach is that the sigmoidal sensor response is maintained (Figure 3a, black squares). The control construct, which lacks the oligonucleotide conformational switch, again shows no such variation in PL response with $\mathrm{pH}$.

The sensor constructs were then endocytosed into HeLa cells by incubation at $37^{\circ} \mathrm{C}$ for 10 minutes. Following rinsing to remove excess sensor, incubation at $37^{\circ} \mathrm{C}$ was continued for $0,10,20$ and 30 minutes prior to imaging. Qualitatively, punctate staining characteristic of endosomes was apparent in all healthy cells examined, with these features closer towards the center of each cell at later time points. As illustrated for the example shown in Figure 3b, the images were processed to calculate the average proportion of green channel fluorescence (see supplementary information for details) for each identifiable endosomal structure within multiple cells at each time point. The ratio values (Figure 3c) show a clear decrease with increasing time, consistent with progressive acidification of the endosomes. No such variation was observed upon incubation of cells with the control construct, which lacks the oligonucleotide conformational switch (Figure S10). Comparing the ratio values with those from the calibration (Figure 3a) reveals an average drop in $\mathrm{pH}$ from $>7.4$ to $<6.9$ over the course of the experiment, with significant numbers of vesicles showing $\mathrm{pH}$ values of $\sim 6.0$ by the last time point recorded.

Our $\mathrm{pH}$ resolution here is limited by the variation in the number of DNA-Rox moieties per QD. The Poisson distribution of stoichiometries that describes the construct population gives rise to a distribution of fluorescence ratios. At the single QD level, individual sensors will exhibit different emission profiles for the same $\mathrm{pH}$, depending on the number of appended DNA-Rox units. This effect becomes significant for endosomes whose sizes can only accommodate on the order of a dozen NC sensors, giving rise to a distribution of measured $\mathrm{pH}$ values at any given time point. While the natural biological variability in $\mathrm{pH}$ amongst endosomes has been found to be as high as $+/-0.2 \mathrm{pH}$ units, ${ }^{[18]}$ the variability in construct stoichiometry can be assigned as the major contributor to the distribution in observed $\mathrm{pH}$ within the same time points observed in this experiment (error bars, Figure $3 \mathrm{c}$ ). This distribution is also reflected in the range of ratios obtained using the non-sensing control constructs (error bars, Figure S7). 
The application of NCs to study complex living systems has the potential to yield molecular level information with unprecedented spatial resolution together with the ability to track changes over long periods of time. Using molecular machines to control the optical properties of $\mathrm{NC}$ constructs presents a new and flexible approach to designing sensors that realize this goal. By transducing a mechanical property rather than an optical property, we separate the sensing and signaling functions. Such sensors are no longer constrained to operate within the parameters defined by available analyte-sensitive fluorophores. The conjugation chemistries employed here are universal and so any FRET pair of fluorophores can be employed, including the attractive possibility of creating all-NC ratiometric sensors. Likewise, the conformational switch may be optimized per analyte and concentration range without necessitating a change to the fluorescent components or imaging setup.

Oligonucleotide conformational switches triggered by other simple stimuli have been characterized, ${ }^{[12]}$ along with DNA-based aptamers that exhibit a conformational change on binding non-nucleotide targets, ${ }^{[19]}$ while the field of supramolecular chemistry has provided a host of synthetic receptors that undergo a conformational change on guest binding. ${ }^{[20]}$ The sensor design reported here demonstrates that any of these systems may be harnessed in a $\mathrm{NC}-$ nanomachine sensor. Achieving control over nanoconstruct stoichiometry is a key challenge that now must be addressed. While applications that involve imaging large numbers of $\mathrm{NC}$ fluorophores (such as mapping the tumor environment) are not limited by the distribution of NC valencies, NC constructs with precisely defined stoichiometry would allow quantitative measurement even for applications involving only a few $\mathrm{NC}$-sensors.

\section{Supplementary Material}

Refer to Web version on PubMed Central for supplementary material.

\section{References}

1. Klajn R, Stoddart JF, Grzybowski BA. Chem. Soc. Rev. 2010; 39:2203-2237. [PubMed: 20407689]

2. a) Bruchez M Jr, Moronne M, Gin P, Weiss S, Alivisatos AP. Science. 1998; 281:2013-2016. [PubMed: 9748157] b) Chan WCW, Nie SM. Science. 1998; 281:2016-2018. [PubMed: 9748158]

3. a) Larson DR, Zipfel WR, Williams RM, Clark SW, Bruchez MP, Wise FW, Webb WW. Science. 2003; 300:1434-1436. [PubMed: 12775841] b) Stroh M, Zimmer JP, Duda DG, Levchenko TS, Cohen KS, Brown EB, Scadden DT, Torchilin VP, Bawendi MG, Fukumura D, Jain RK. Nat. Med. 2005; 11:678-682. [PubMed: 15880117] c) Bruns OT, Ittrich H, Peldschus K, Kaul MG, Tromsdorf UI, Lauterwasser J, Nikolic MS, Mollwitz B, Merkel M, Bigall NC, Sapra S, Reimer R, Hohenberg H, Weller H, Eychmüller A, Adam G, Beisiegel U, Heeren J. Nature Nanotech. 2009; 4:193-201.

4. Medintz IL, Uyeda HT, Goldman ER, Mattoussi H. Nature Mater. 2005; 4:435-446. [PubMed: 15928695]

5. Somers RC, Bawendi MG, Nocera DG. Chem. Soc. Rev. 2007; 36:579-591. [PubMed: 17387407]

6. a) Suzuki M, Husimi Y, Komatsu H, Suzuki K, Douglas KT. J. Am. Chem. Soc. 2008; 130:57205725. [PubMed: 18393422] b) Boeneman K, Mei BC, Dennis AM, Bao G, Deschamps JR, Mattoussi H, Medintz IL. J. Am. Chem. Soc. 2009; 131:3828-3829. [PubMed: 19243181]

7. a) Medintz IL, Clapp AR, Mattoussi H, Goldman ER, Fisher B, Mauro JM. Nature Mater. 2003; 2:630-638. [PubMed: 12942071] b) Freeman R, Finder T, Bahshi L, Willner I. Nano Lett. 2009; 9:2073-2076. [PubMed: 19354297]

8. a) Freeman R, Gill R, Shweky I, Kotler M, Banin U, Willner I. Angew. Chem. 2009; 121:315-319. Angew. Chem. Int. Ed.2009, 48, 309-313. b) Wang S, Han M-Y, Huang D. J. Am. Chem. Soc. 2009; 131:11692-11694. [PubMed: 19645465]

9. Medintz IL, Stewart MH, Trammell SA, Susumu K, Delehanty JB, Mei BC, Melinger JS, BlancoCanosa JB, Dawson PE, Mattoussi H. Nature Mater. 2010; 9:676-684. [PubMed: 20651808]

10. a) Snee PT, Somers RC, Nair G, Zimmer JP, Bawendi MG, Nocera DG. J. Am. Chem. Soc. 2006; 128:13320-13321. [PubMed: 17031920] b) Dubach JM, Harjes DI, Clark HA. J. Am. Chem. Soc. 2007; 129:8418-8419. [PubMed: 17567136] c) Chen Y, Thakar R, Snee PT. J. Am. Chem. Soc. 
2008; 130:3744-3745. [PubMed: 18321112] d) Suzuki M, Husimi Y, Komatsu H, Suzuki K, Douglas KT. J. Am. Chem. Soc. 2008; 130:5720-5725. [PubMed: 18393422] e) McLaurin EJ, Greytak AB, Bawendi MG, Nocera DG. J. Am. Chem. Soc. 2009; 131:12994-13001. [PubMed: 19697933] f) Jin T, Sasaki A, Kinjo M, Miyazaki J. Chem. Commun. 2010; 46:2408-2410.g) Krooswyk JD, Tyrakowski CM, Snee PT. J. Phys. Chem. C. 2010; 114:21348-21352.h) Wang X, Boschetti C, Ruedas-Rama MJ, Tunnacliffe A, Hall EAH. Analyst. 2010; 135:1585-1591. [PubMed: 20449508] i) Page LE, Zhang X, Jawaid AM, Snee PT. Chem. Commun. 2011; 47:7773-7775.j) Somers RC, Lanning RM, Snee PT, Greytak AB, Jain RK, Bawendi MG, Nocera DG. Chem. Sci. 2012; 3:2980-2985.

11. a) Albertazzi L, Storti B, Marchetti L, Beltram F. J. Am. Chem. Soc. 2010; 132:18158-18167. [PubMed: 21141854] b) Tantama M, Hung YP, Yellen G. J. Am. Chem. Soc. 2011:10034-10037. [PubMed: 21631110]

12. Bath J, Turberfield AJ. Nature Nanotech. 2007; 2:275-284.

13. Modi S, Swetha MG, Goswami D, Gupta GD, Mayor S, Krishnan Y. Nature Nanotech. 2009; 4:325-330.

14. Brucale M, Zuccheri G, Samorí B. Org. Biomolec. Chem. 2005; 3:575-577.

15. Liu WH, Greytak AB, Lee J, Park J, Worng CR, Marshall LF, Jiang W, Curtin PN, Ting AY, Nocera DG, Jain RK, Bawendi MG. J. Am. Chem. Soc. 2010; 132:472-483. [PubMed: 20025223]

16. Pons T, Medintz IL, Wang X, English DS, Mattoussi H. J. Am. Chem. Soc. 2006; 128:1532415331. [PubMed: 17117885]

17. Mellman I, Fuchs R, Helenius A. Annu. Rev. Biochem. 1986; 55:663-700. [PubMed: 2874766]

18. Serresi M, Bizzarri R, Cardarelli F, Beltram F. Anal. Bioanal. Chem. 2009; 393:1123-1133. [PubMed: 19034435]

19. Liu JW, Cao ZH, Lu Y. Chem. Rev. 2009; 109:1948-1998. [PubMed: 19301873]

20. Kovbasyuk L, Krämer R. Chem. Rev. 2004; 104:3161-3187. [PubMed: 15186190] 


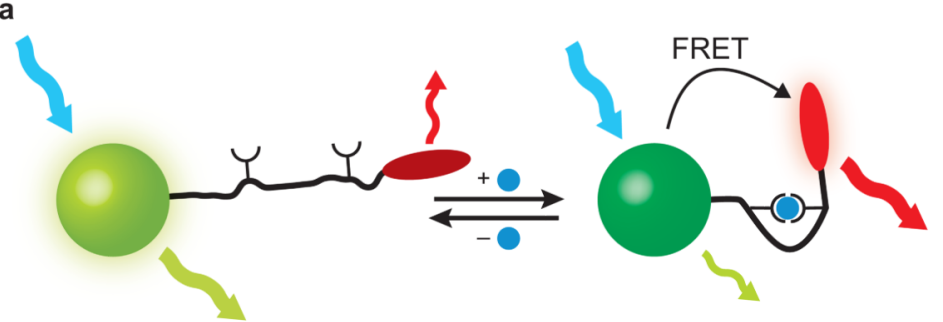

C

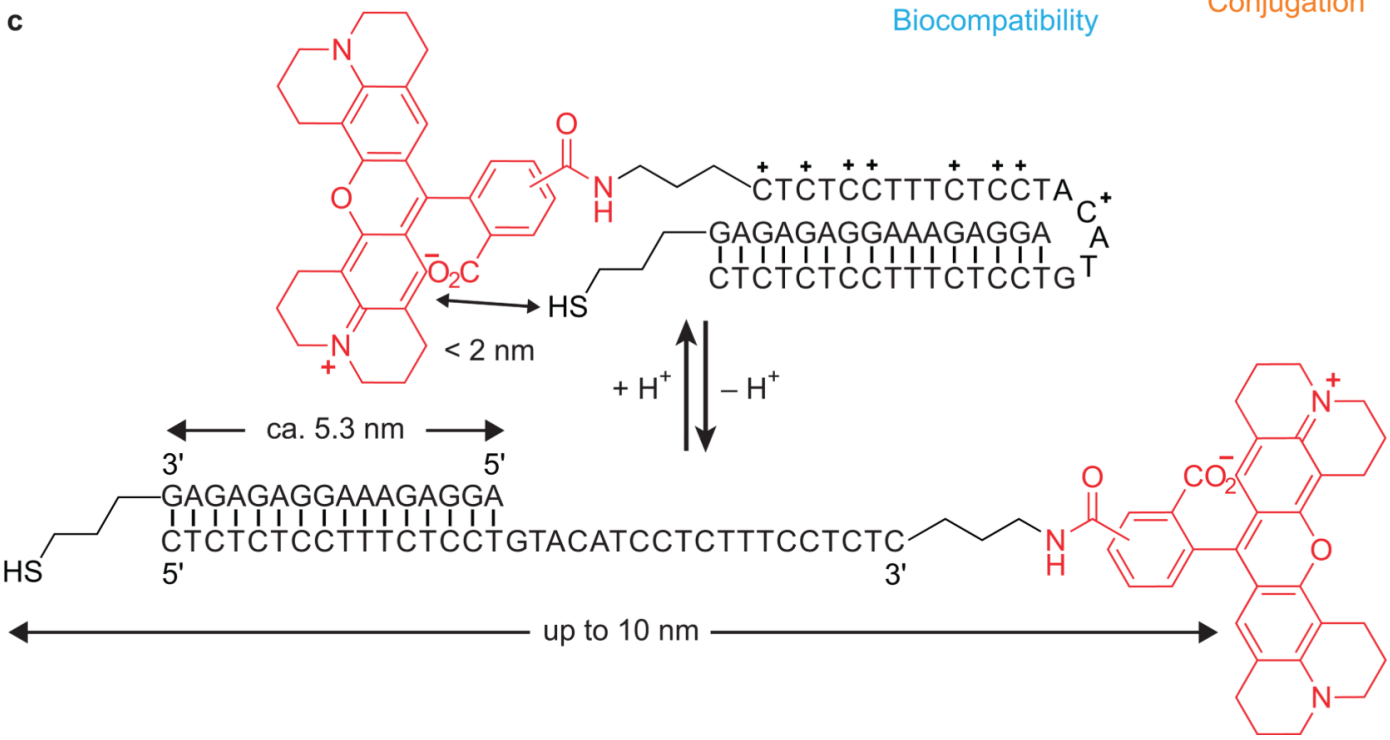

b<smiles>[Z]C(C)(CC(C)(C)C(C)(C)CC(C(=O)NCCc1cnc[nH]1)C(C)(C)CC(C(=O)NCCC(C)(C)N)C(C)(C)Cc1ccccc1)C(=O)NCCOCC(C)(C)N</smiles>

Figure 1.

Sensor design and constituent parts. a) Schematic illustration of sensor design wherein a fluorescent NC (green) is conjugated to one or several molecular fluorophores (red) through an analyte-sensitive linker. Binding of a specific analyte (blue) to the linker triggers a conformational change that alters the donor-acceptor distance, hence changing the FRET efficiency and therefore eliciting a wavelength ratiometric optical response. b) Chemical structure of PIL ligand 1. Monomer units were arranged randomly; ratio x:y:z was 1:2:1, and typically $\mathrm{x}+\mathrm{y}+\mathrm{z}=\mathrm{n} \sim 16$ (i.e., an average of 32 monomer units per chain). c) pH-Responsive oligonucleotide triplex-duplex conformational switch, bearing carboxy-X-rhodamine and thiol functionalities. Not drawn to scale. 

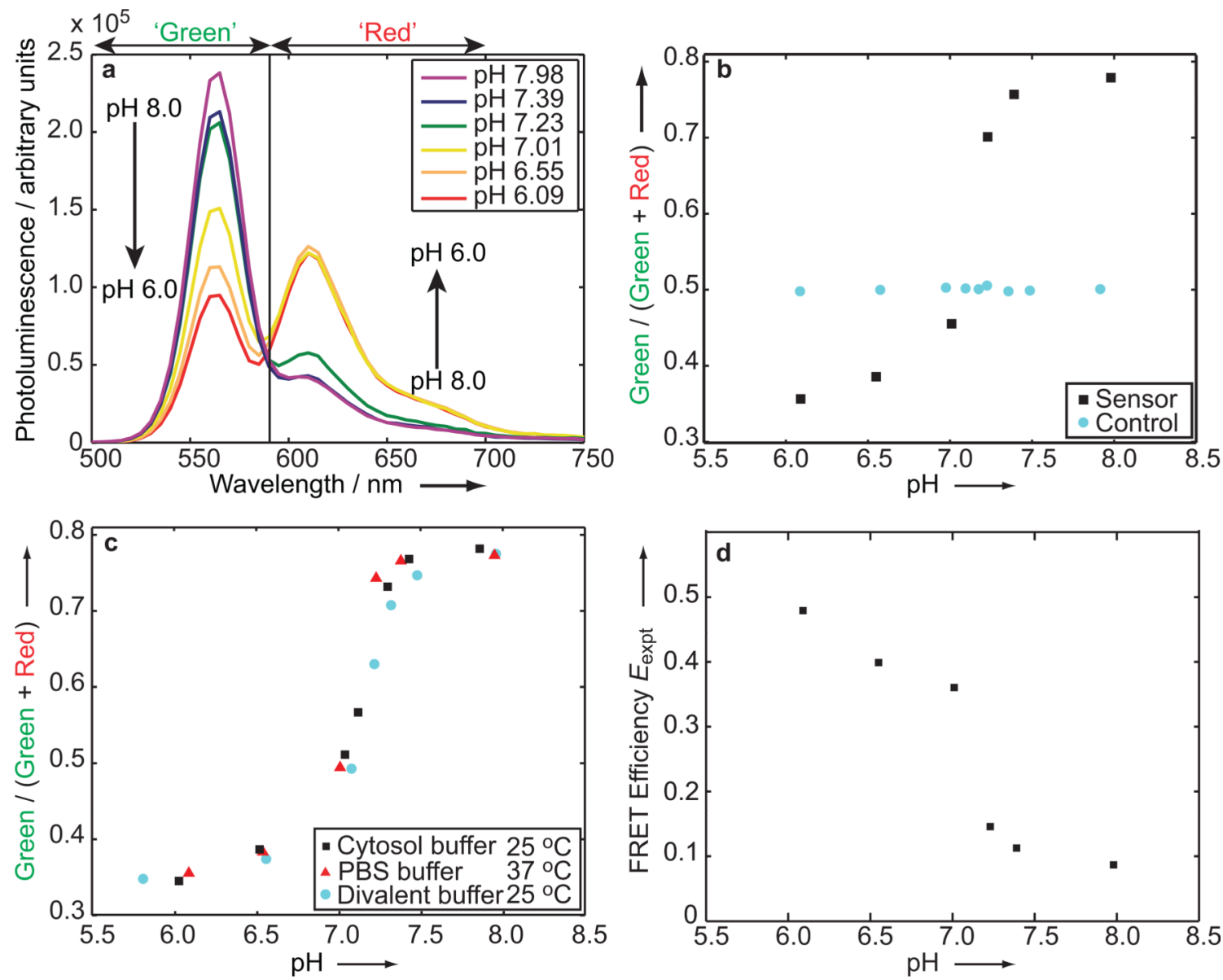

e
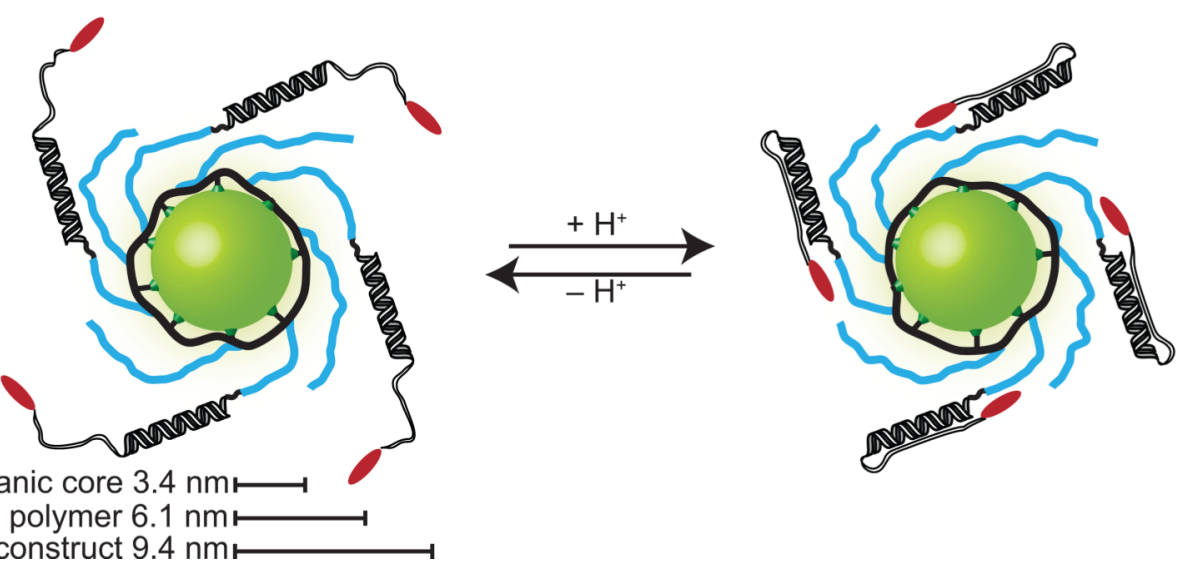

Inorganic core $3.4 \mathrm{~nm}$ $\mathrm{QD}+$ polymer $6.1 \mathrm{~nm}$

Sensor construct $9.4 \mathrm{~nm}$

Figure 2.

Spectroscopic characterization of the sensor. a) Sensor photoluminescence spectra on excitation at $460 \mathrm{~nm}$ in PBS buffers with differing $\mathrm{pH}$ values at $25{ }^{\circ} \mathrm{C}$. Solid black line at $590 \mathrm{~nm}$ indicates cutoff wavelength for integration of intensities in 'green' and 'red' channels. Spectra were corrected for variation in concentration using absorbance measurement at excitation wavelength. b) Proportion of total emission intensity in 'green' channel (as defined in a) as $\mathrm{pH}$ is varied at $25^{\circ} \mathrm{C}$ for the sensor (black squares) and a control NC-Rox construct that lacks the oligonucleotide switch. c) Sensor performance under varying environmental conditions. PBS (phosphate buffered saline): (10 mM phosphate, 137 $\mathrm{mM} \mathrm{Na}^{+}, 2.7 \mathrm{mM} \mathrm{K}^{+}$); Cytosol buffer: $10 \mathrm{mM}$ phosphate, $139 \mathrm{mM} \mathrm{K}+, 12 \mathrm{mM} \mathrm{Na}^{+}$; 
Divalent buffer: $12 \mathrm{mM}$ phosphate, $137 \mathrm{mM} \mathrm{NaCl}, 2.7 \mathrm{mM} \mathrm{KCl}, 0.9 \mathrm{mM} \mathrm{Ca}^{2+}, 0.5 \mathrm{mM}$ $\mathrm{Mg}^{2+}$. d) Efficiency of energy transfer from NC to Rox components with varying $\mathrm{pH}$. e) Cartoon representation of sensor construct and operation, indicating inorganic core radius as determined by TEM and hydrodynamic radii of unfunctionalized and functionalized watersoluble NC constructs, as determined by DLS (see supplementary information for further details). 
a

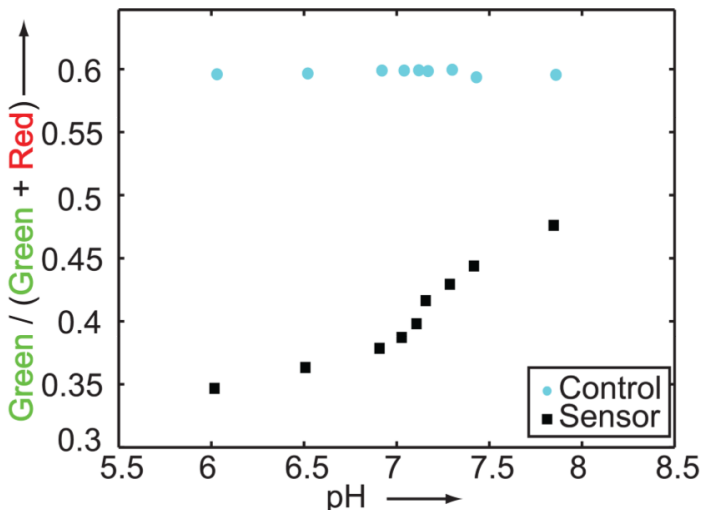

b

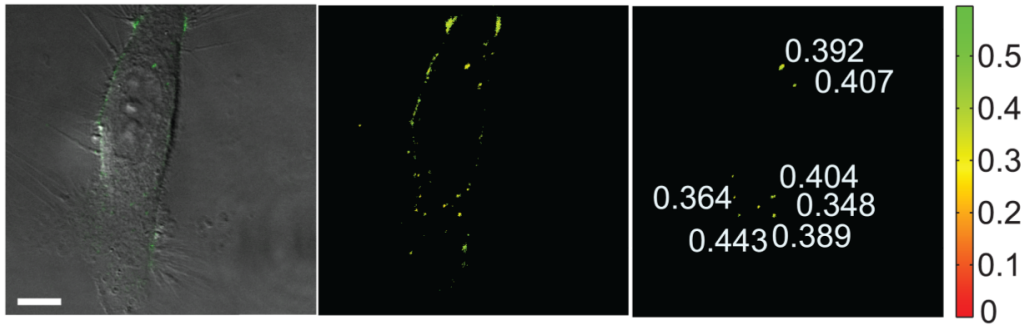

\begin{tabular}{|c|c|c|c|}
\hline Endosome (min) & Mean G/(G+R) & SD & n \\
\hline $10 \mathrm{~min}$ & 0.447 & \pm 0.014 & 10 \\
\hline $10 \mathrm{~min}+10 \mathrm{~min}$ & 0.437 & \pm 0.021 & 35 \\
\hline $10 \mathrm{~min}+20 \mathrm{~min}$ & 0.408 & \pm 0.017 & 15 \\
\hline $10 \mathrm{~min}+30 \mathrm{~min}$ & 0.384 & \pm 0.020 & 31 \\
\hline
\end{tabular}

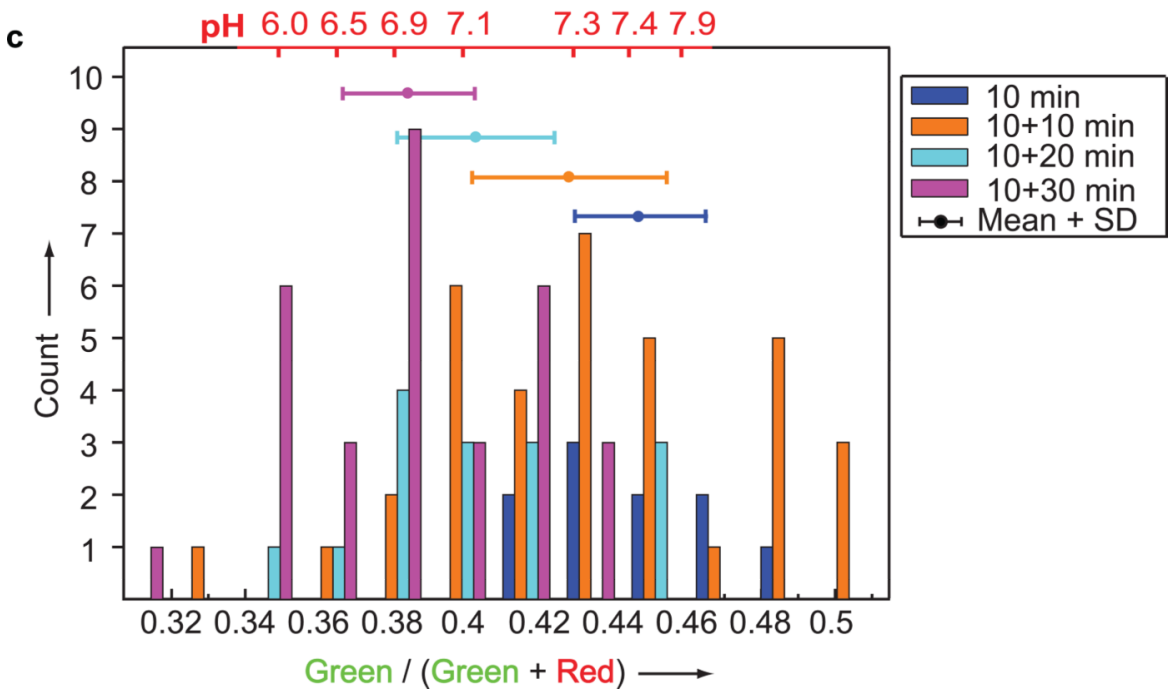

Figure 3.

Application of sensor for confocal imaging of endosomal $\mathrm{pH}$ in live cells. a) Proportion of total emission in green channel on confocal imaging of the sensor (black squares) and the control (blue circles) constructs in phosphate buffers with varying $\mathrm{pH}$. b) Representative raw image, false-colored ratiomap, and picked endosomes of a cell from the $10 \mathrm{~min}+20$ minute group. c) Emission ratios for endosomes found in cells incubated with the sensor construct for a 10 minute pulse period followed by 0,10 minute, 20 minute, and 30 minute chase periods (endosome $\mathrm{n}=11,36,16,31$ respectively). (Scale bar $=10 \mu \mathrm{m})$ 